\title{
Kajian Toleransi Dalam Teks Cerita Rakyat Masyarakat Rote di Nusa Tenggara Timur
}

\author{
Iswanto* \& Marsi Bombongan Rantesalu \\ Intitut Agama Kristen Negeri Kupang \\ *iswantoyohanes@rocketmail.com
}

DOI: https://doi.org/10.34307/b.v3i2.126

\begin{abstract}
Tolerance as a value is manifested in the life behavior of a group of people. The aim of this study is to analyze and describe tolerance studies based on the folklore of the people of Rote in East Nusa Tenggara. As research conducted by Rantesalu and Iswanto (2018), defines tolerance values based on the stories of the people of the Toraja community, namely the value of acceptability and understanding combined with togetherness and complementary. Another empirical paradigm was obtained from Hofner (2018) which explains the tolerance is influenced by social and political contexts. This research is focused on the specificity of the perception of tolerance that is formed from values based on folklore data. The method used is descriptive qualitative method and enriched with Ricour hermeneutic method in text analysis. The data obtained in the form of a folklore titled Landu, which tells the history of the formation of the Landu community on the island of Rote. The Landu Kingdom is one of the 19 kingdoms on Rote Island in the 14th century. Based on the data obtained the results of research on tolerance values contained in CRMR Landu are (1) This acceptability and understanding as a base the basis of tolerance is explained by the verb diadik loke // hule 'beri // kasih' and (2) the value of brotherhood based on the form of diadik dalek // teik 'rasa // inner', inak // touk 'father // mother '.
\end{abstract}

Keywords: Tolerance, Text, Value

Abstrak: Toleransi sebagai sebuah nilai diwujudkan dalam perilaku kehidupan suatu kelompok masyarakat. Tujuan penelitian ini ialah meganalisa dan mendeskripsikan kajian toleransi berdasarkan cerita rakyat masyarakat Rote di Nusa Tenggara Timur. Sebagaimana penelitian yang dilakukan oleh Rantesalu dan Iswanto (2018), mendefinisikan nilai toleransi berdasarkan ceritera rakyat masyarakat Toraja yang di dalamnya terdapat internalisasi nilai keberterimaan dan kesepahaman (acceptability and understanding). Selanjutnya, nilai-nilai tersebut disejajarkan dengan kebersamaan (togetherness) dan saling melengkapi (complementary). Paradigma empiris lainnya diperoleh dari Hofner (2018) yang menjelaskan toleransi yang ditimbulkan dari konteks politik di Indonesia. Penelitian ini lebih difukuskan pada kekhasan persepsi toleransi yang terbentuk dari nilai berdasarkan data cerita rakyat. Penelitian ini menggunakan pendekatan deskriptif kualitatif yang diperkaya dengan metode hermeneutik Ricour dalam analisa teks. Data yang diperoleh berupa cerita rakyat berjudul Landu, yang menceritakan sejarah terbentuknya masyarakat Landu di pulau Rote. Kerajaan Landu adalah salah satu kerajaan dari 19 kerajaan di Pulau Rote pada abad ke-14. Berdasarkan data diperoleh hasil penelitian nilai toleransi yang terdapat dalam CRMR Landu adalah (1) Nilai keberterimaan dan kesepahaman (acceptability and understanding) ini 
sebagai alas dasar toleransi dijelaskan berdasarkan verba diadik loke//hule 'beri//kasih' dan (2) nilai persaudaraan (brotherhood) yang berdasarkan pada bentuk diadik dalek//teik 'rasa//batin', inak//touk 'ayah//ibu'.

Kata Kunci: Toleransi, Teks, Landu

\begin{tabular}{llll}
\hline Article History : & Received: 14-10-2019 & Revised: 25-09-2020 & Accepted:30-09-2020 \\
\hline
\end{tabular}

\section{Pendahuluan}

Manusia sebagai makhluk berbudaya menandai fenomena di sekitarnya dalam konteks yang berkembang secara teratur hingga membentuk sebuah sistem yang tercermin dalam ide, nilai, norma, dan peraturan. Pengungkapan fenomena tersebut dapat secara verbal ataupun non verbal, diturunkan dari satu generasi ke generasi, membentuk kognisi budaya dan terlihat dalam perilaku 1. Fonomena kebahasaan sebagai produk budaya memberikan gambaran pemaknaan manusia dalam memandang suatu nilai kultus. ${ }^{2}$ Bahasa yang bersifat konseptual dihasilkan dari pengalaman yang hierarkis dan lama-kelamaan membentuk sistem konseptual kognisi individu yang berkembang dalam masyarakat pengguna. ${ }^{3}$ Pada tataran ini, bahasa sebagai sarana pembentuk gagasan merekonstruksi persepsi individual dalam sebuah pemaknaan budaya, baik secara mikrokosmos maupun makrokosmos. Hakikat tersebut menjadi media untuk memahami dan menjelaskan realitas budaya dalam masyarakat. ${ }^{4}$ Agama sebagai sebuah realita dibangun dalam tatanan budaya, dalam kaitanya dengan konsep ini kosmologi menjadi bagian penting dari sistem agama dan budaya. ${ }^{5}$

Dalil sosiokultural pada bagian ini, dapat memberikan pemahaman yang kompleks mengenai peristiwa-peristiwa yang ada di masyarakat. Berkaitan dengan hal penjelasan tersebut, konsep toleransi merupakan hal penting yang ada dalam kehidupan masyarakat. Toleransi sendiri dapat dipandang sebagai sebuah fenomena yang tidak hanya dideskripsikan berdasarkan satu etimologi tetapi lebih kepada realita pada masyarakat yang beragam. Pemikiran ini dapat ditelusuri dari berbagai fenomena

\footnotetext{
${ }^{1}$ Paul J. Thibault, Re-Reading Saussure: The Dynamics of Signs in Social Life (London ; New York: Routledge, 1997).

2 Danesi, Marcel, A Basic Course in Anthropological Linguistic (Toronto: Canadian Scholar's Press inc, 2004).

${ }^{3}$ Ibid.

${ }^{4}$ James J Fox, "The Poetic Power of Place: Comparative Perspectives on Austronesian Ideas of Locality" (n.d.): 89-93.

${ }^{5}$ Sonny Zaluchu and Fransiskus Widjaja, "A Phenomenology Approach: Religious Significance of Mandala in Ancient Nias Culture," in Proceedings of the Proceedings of the 1st Seminar and Workshop on Research Design, for Education, Social Science, Arts, and Humanities, SEWORD FRESSH 2019, April 27 2019, Surakarta, Central Java, Indonesia (Presented at the Proceedings of the 1st Seminar and Workshop on Research, http://eudl.eu/doi/10.4108/eai.27-4-2019.2286915. 1-2
} 
sosiokultural kelompok-kelompok masyararakat di Indonesia. ${ }^{6}$ Secara etimologi, kata toleransi berasal dari bahasa latin tolerance yang berarti kemampuan menahan diri yang disertai dengan sikap sabar dan membiarkan orang lain memeberikan pendapat. Dapat juga disamakan dengan sikap berhati lapang terhadap orang dengan berda pendapat.7 Sikap toleransi berbeda dengan pembenaran terhadap sebelah pihak saja, tetapi lebih kepada pengakuan kebebasan hak asasi para penganutnya. Lebih lanjut, dalam konteks yang lebih luas toleransi juga dapat diartikan sebagai sikap saling menghargai kelompok - kelompok dalam masyarakat. Dalam aras persepsi yang lebih luas, toleransi dianggap sebagai properti dari sistem nilai sosiokultural. ${ }^{8}$ Individu yang toleran mampu menempatkan nilai simbolis tidak hanya untuk karakteristiknya sendiri tetapi juga untuk orang-orang yang tidak dia miliki. Sebaliknya, orang yang tidak bertoleransi memiliki sistem nilai yang tidak seimbang yang ditandai dengan sikap berpuas diri dan tidak hormat sifat kepada orang lain. ${ }^{9}$

Paradigma paktis sebagai bagian dari latar belakang dapat kita lihat dalam fenomena keadaan masyarakat Rote secara etnografis. Pulau Rote secara geografis terletak berada di ujung paling selatan batas negara Indonesia. Kabupaten ini merupakan salah satu kebupaten di Provinsi Nusa Tenggara Timur (NTT). Provonsi NTT sendiri terdiri dari beberapa pulau besar diantaranya pulau Flores, Sumba, Timor, Adonara, Lembata, Alor, Sabu, dan Rote Pulau Rote dan Ndao. Rote dan Ndao secara administratif menjadi sebauh kabupaten yang dikenal dengan nama kabupaten RoteNdao. Pusat pemerintah kabupaten terletak di Kota Ba'a Kecamatan Lobalain.

Kabupaten Rote Ndao secara administratif dibagi menjadi Kecamatan Rote Barat Daya, Kecamatan Ndao Nuse, Kecamatan Rote Tengah, Kecamatan Rote Timur, Kecamatan Rote Barat Laut, Kecamatan Rote Selatan, Kecamatan Lobalain, Kecamatan Landuleko, dan Kecamatan Pantai Baru. Sistem mata pencaharian yang masyarkat bertumpu pada kegiatan bertani di sawah dan di ladang. Selain itu, kerajinan tangan juga akhir-akhir ini digeluti oleh sebagian masyarakat diantaranya tenun ikat, menganyam berbagai keperluan keseharian seperti topi, tas, dan berbagai bentuk kriya lainnya. Berdasarkan catatan sejarah masyarakat Rote juga berkerja sebagai penyadap lontar, dan nelayan bagi terutama bagi masyarakat pesisir. Mata pencaharian tenun ikat menjadi permasalahan yang dibahas selanjutnya.

\footnotetext{
${ }^{6}$ Akhiyat Akhiyat, "Debates on Religious Studies In the Phenomenology Perspective and Its Contribution to Interfaith Tolerance," Ulumuna 23, no. 1 (June 28, 2019): 163-192.

${ }^{7}$ Corneo, Giacomo dan Olivier Jeanne, $A$ Theory of Tolerance (London: Johns Hopkins University, 2009).

${ }^{8}$ Robert W. Hefner and Barbara Watson Andaya, eds., Routledge Handbook of Contemporary Indonesia, Routledge handbooks (Abingdon, Oxon ; New York, NY: Routledge, 2018).

${ }_{9}^{9}$ Marsi Bombongan Rantesalu and Iswanto Iswanto, "Toleransi Berdasarkan Cerita Rakyat Tallu To Sala' Dadi di Toraja," BIA': Jurnal Teologi dan Pendidikan Kristen Kontekstual 1, no. 1 (December 30, 2018): 13-25.
} 
Secara empiris penelitian ini menempatkan beberapa penelitian sebelumnya yaitu penelitian Rantesalu dan Iswanto (2018) yang berjudul Toleransi Berdasarkan Cerita Rakyat Tallu To Sala'Dadi di Toraja. Penelitian tersebut menyimpulkan empat nilai toleransi yaitu: internalisasi nilai keberterimaan dan kesepahaman (acceptability and understanding). Selanjutnya, nilai-nilai tersebut disejajarkan dengan kebersamaan (togetherness) dan saling melengkapi (complementary). Penelitian yang dilakukan oleh Rantesalu dan Iswanto (2018) masih dirasa perlu untuk dikembangkan dalam penelitian lanjutan sebagaimana rekomendasi yang diberikan. Oleh karena itu, penelitian ini mengambil seting lokus yang berbeda untuk mencari nilai-nilai toleransi nusantara untuk memperkaya makna dalam kehidupan beragama. ${ }^{10}$ Selanjutnya penelitian Hefner (2018) dalam bukunya Routledge Handbook of Comtemporary Indonesia. Buku ini membahas berbagai fenomena plurasisme, agama, dan gender yang berkembang di Indonesia. ${ }^{11}$ Pemahaman Hefner ini selanjutnya mempertemukan dua pemikiran yaitu pengaruh budaya asli peraturan pemerintah yang menjadi aras perkembangan kehidupan beragama di Indonesia. Pemikiran Hefner (2018) memberikan gambaran tentang Kajian toleransi dalam penelitian ini. Pemikiran ini tidak sepenuhnya digunakan, oleh karena Hefner (2018) hanya menitik beratkan kepada kehidupan beragama sedangkan penelitian ini mencoba melihat toleransi tidak sebatas pada kehidupan beragama itu sendiri tetapi lebih kepada kekhasan masyarkat Rote di Nusa Tenggara Timur.

Penelitian ini diharapkan dapat memberikan kontribusi konseptual tentang atribut-atribut toleransi yang khas bersumber dari makna budaya. Hal ini tentunya dapat dikaitkan dengan pentingnya toleransi dalam kehidupan berbangsa dan bernegara di Indonesia. Ranah yang lebih luas diharapkan juga terus bersinergi dalam membangun kehidupan toleransi yang komprehensif dan terintegrasi. ${ }^{12}$

Berdasarkan pembahasan di atas permasalahan dalam penelitian ini ialah bagaimana kajian toleransi dalam teks CRMR di Nusa Tenggara Timur ? Tujuan yang ingin dicapai ialah menganalisa dan mendeskrpsikan kajian toleransi dalam teks CRMR di Nusa Tenggara Timur.

\footnotetext{
${ }^{10}$ Corneo, Giacomo dan Olivier Jeanne, $A$ Theory of Tolerance.

${ }^{11}$ Hefner and Andaya, Routledge Handbook of Contemporary Indonesia.

${ }^{12}$ Theodora van Bowen, "RELIGIOUS EDUCATION FOR TOLERANCE," Utrecht (2016): 59.
} 


\section{Teori}

Penelitian ini menggunakan teori mitologi yang dikembangkan oleh Barthes. Teori mitologi Barthes dibedakan menjadi empat kajian, yaitu: 1) Mitos sebagai Tipe wicara (Type of Speech); 2) mitos sebagai sistem semiologi; 3) mitos sebagai wicara yang didepolitisasi. ${ }^{13}$

\section{Mitos sebagai Wicara (Type of Speech)}

Mitos sebagai jenis wicara artinya mitos sebagai sistem komunikasi untuk menyampaikan suatu pesan. Mitos sebagai wicara berkaitan dengan bahasa sebagai wahana mitos itu berkembang. Pengertian mitos lebih menekankan pada sebuah cara pemaknaan; dalam paradigma Barthes lebih dikenal dengan tipe wicara.

Mitos sebagai tipe wicara Barthes menurut Arthur adalah bahasa sebagai wahana mitos berkembang. Pemahaman komprehensif terdapat sebuah mitos berarti mengerti sebuah pesan dari wahana tersebut. Pengertian mitos tidak berkaitan dengan konsep mitos secara denotatif atau pengertian sehari-hari, melainkan sebuah cara pemaknaan yang ditimbulkan dari pesan. Mitos tidak tergantung pada objek dan konteks, tetapi mempunyai cara tersendiri dalam menyampaikan pesan. Pendekatan kealamihan dan berkaitan dengan realitas keseharian merupakan strategi kognitif konseptual sebuah mitos untuk tetap mempertahankan maknanya. Keterbukaan terhadap konteks diartikan melebihi teks sehingga mitos terus dibicarakan sebagai sebuah realita yang terbuka dalam masyarakat. Dengan cara demikian, semua objek akan diungkapkan dengan silih berganti dan bukan bersamaan dalam satu frame waktu.

\section{Mitos sebagai Sistem Semiologi (Semiology System)}

Semiologi berasal dari kata semeion yang berarti tanda, ilmu yang tentang tanda, sistem tanda dan penanda. Pemikiran ini diuangkap pertama kali oleh seorang ahli linguistik yang bernama Ferdinan de Saussure. Keterpaduan relasi ini juga dikenal dengan istilah signifier dan signified atau disebut penanda dan petanda. Lebih lanjut Barthes mengatakan mitos dalam semiologi, berarti mitos merupakan tipe wicara dengan kumpulan tanda dan asosiatif di dalamnya. ${ }^{14}$

\section{Mitos Sebagai Wacana yang Didepolitisasi}

Mitos sebagai wacana yang didepolitisasi adalah menjelaskan keberadaan mitos yang difungsikan sebagai sebuah justifikasi alamiah yang beriaktan secara tidak langsung dengan sejarah, dan memuat sebuah kemungkinan terus diceritakan dari generasi ke generasi. Mitos dipandang secara formal sebagai intrumen yang paling sesuai untuk pembalikan ideologis pada level komunikasi manusia. Pendapat ini juga

\footnotetext{
${ }^{13}$ Barthes, Roland, Mitologi. (Terj. Nurhadi \& Sihabul Millah) (Yogyakarta: Kreasi, n.d.).

${ }^{14}$ Ferdinant de Saussure, Pengantar Linguistik Umum (Yogyakarta: Gajah Mada University Press, 1993).
} 
diartikan bahwa mitos sebenarnya bukan bersifat politis, tetapi lebih kepada konsep kognitif sosial masyarkaat. Oleh karena itu, mitos membicarakan berbagai hal dalam ideologi masyarakt dan menjadi teks alamiah dan bersifat abadi.

Selain teori mitologi dari Barthes, penelitian ini juga menggunakan teori semiotik kognitif. ${ }^{15}$ Cara kerja teori ini ialah menginterpretasi tanda dapa tiga tingkatan ke dalaman makna. Tiga tingkatan tersebut ialah: 1)subjektif (persepsi); 2)intersubjektif (sistem penandaan) dan 3) objektif (hubungan tanda). Prinsip ini mengelolah tanda yang hadir melalui leksikon budaya untuk menjadi kesatuan alur pikir dan mengarah pada ideologi. 16

\section{Metode Penelitian}

Penlitian ini tergolong dalam kualitatif dengan ciri fenomenologi berdasarkan aras filsafat realisme Plato. ${ }^{17}$ Paradigma penelitian kualitatif menempatkan masalah bersifat sementara atau tentative dan akan berkembang berdasarkan fenomena di lapangan. Temuan dalam penelitan kualitatif tidak melibatkan prosedur statistik atau rumusan matematis dalam proses hasil dan pembahasan. Dengan kata lain, penelitian kualitatif bertujuan untuk memahami fenomena atau gejala sosial berdasarkan pada gambaran yang lengkap yang dikaji secara mendalam dengan teknik interpretasi daripada penjelasan tabulatif berdasarkan variabel-variabel yang saling terkait. Dengan cara seperti ini, diperoleh pemahaman tentang fenomena dan kekompleksan asosiasi konseptual untuk selanjutnya menjadi teori. ${ }^{18}$

Lebih lanjut, penelitian kualitatif menjelaskan keterkaitan masalah dengan peneliti itu sendiri, dijelaskan sebagai berikut: (1) peneliti dapat mempertahankan masalah hingga akhir proses penelitian. Hal ini mungkin terjadi karena sistematik leteratur yang sejalan dan bersifat tetap dalam kurun waktu penelitian tertentu, (2) seringkali masalah berkembang setelah peneliti berada di lapangan. Hal ini mungkin terjadi karena perluasan dan kedalaman interpretasi yang dirasa perlu dilakukan oleh peneliti. Dalam situasi ini tidak akan terjadi banyak perubahan sehingga judul penelitian cukup disempurnakan, (3) perubahan total masalah yang dibawa peneliti setelah memasuki lapangan sehingga masalah tersebut mejadi tidak relevan dan harus diganti sehingga berpadanan dengan judul proposal. Bisa saja judul penelitian diganti.

15 Jordan Zlatev, "Cognitive Semiotics: An Emerging Field for the Transdisciplinary Study of Meaning," Public Journal of Semiotics 4, no. 1 (October 1, 2012): 2-24.

16 Iswanto, et al, "Supernatural Signification System Amuf on Death Ritual Speech Nen Fen Nahat in Boty Society," International Journal of Linguistics, Literature and Culture, 4(2), March 2018, 46-57 Vol 4 No 2 (2018), Retrieved from https://sloap.org/journals/index.php/ijllc/article/view/87.

${ }^{17}$ Anthony Andurand and Corinne Bonnet, "The Divine Plato among Greeks and Romans: Banquet Literature and the Making of Cultural Memory in the Graeco-Roman Empire" (2018): 1

18 Shaun Gallagher and Dan Zahavi, The Phenomenological Mind: An Introduction to Philosophy of Mind and Cognitive Science, Repr. (London: Routledge, 2010). 
Paradigma ini dianggap baik karena prinsip kejenuhan data yang harus ditaati oleh peneliti dalam proses pengambilan data dan analisa data. Sehingga timing penelitian lapangan sangat bergantung pada berubah atau tidaknya cakupan data yang diperoleh. Konsep selanjutnya, perubahan esensi dipandang sebagai pengutamaan data melebihi asumsi awal yang dibangun oleh peneliti sebelum turun lapangan. Fenomena berkembang dalam situasi sosial yang dapat dilihat dari berbagai. Ketetapan yang perlu diperhatikan oleh peneliti ialah gejala dari suatu obyek sebenarnya bersifat tunggal dan parsial. Berdasarkan ketetapan tersebut peneliti seharusnya dapat menentukan variabel-variabel yang akan diteliti. Gejala fenomenologi bersifat holistik (menyeluruh, tidak dapat dipisah-pisahkan) meliputi (1) tempat - place, (2) pelaku - actor, (3) aktivitas - activity, yang ketiganya hadir dan berinteraksi dalam sinergi sosial.

Lebih lanjut, pengdokumentasian studi teks merupakan salah satu pendekatan metodologi dalam lingkup kajian penelitian penelitian kualitatif dengan fokus pada analisis dan interpretasi mendalam terhadap teks dan konteksnya. ${ }^{19}$ Sumber data lainya bisa berupa artikel atau jurnal terpublikasikan, buku teks, surat kabar, majalah, suratsurat, film, catatan harian, naskah, artikel, dan sejenisnya. Usaha untuk mencapai kredibilitas yang tinggi dengan memberikan catatan atau sitasi keotentikan naskahnaskah tersebut. Penelitian jenis bisa juga terkait dengan interpretasi kognitif yang bersifat konseptual.

\section{Hasil Dan Pembahasan}

\section{Transkripsi Ceritera Rakyat Asal-Muasal Landu/Lanu}

Hida bei fan ma dato bei don ele

Bei ta lae Landu

Te ala loke lae Tanalai

Ma ala hule lae Mae Oe

Ma Setimori do Tenalai

Sotido do Saudo, ma Balodo do Oulilo

Ala aki dae do ala bala tola
Di waktu yang lampau dan dimasa silam

Belum di sebut Landu

Tetapi mereka memberikan sebutan Tenalai

Dan mereka memberi nama Mae Oe

Dan Sotimori atau Tenalai

Satido atau Saudo, dan Balodo atau Oelilo

Mereka memberi nama atau mereka

memberi sebutan demikian

${ }_{19}$ Paul Ricœur and John B. Thompson, Hermeneutics and the Human Sciences: Essays on Language, Action, and Interpretation (New York: Cambridge University Press, 2016). 
BIA': Jurnal Teologi dan Pendidikan Kristen Kontekstual, Vol 3, No 2 (Desember 2020)

Ala loke do ala hule lae leo ndiana

Hu hida bei fan na ma dati bei don ele na

Touk ala manaseko metik, ma manasolo nikala

Do taek ala manandai tasila, ma manasolo poek ala

Laka bua-bua buna, ma la'e sado

leme Mae oe

do Sotimoro ma selan te tini tihi

hu ala dalek esa leo inak esa bobongis

ma ala teik esak leo touk easa lalaen de lalek ala dadi

Ma ladak ala moli

Hu ndia de, ala aki dae do ala bala tola

ma ala hule do loke lae

\section{Tenalai do Mae Oe}

Sotimori do Tenalai

Sotido do Saudo

ma Balado do Oulilo
Karena pada zaman dahulu dan di masa yang silam

Lelaki penangkap ikan dan pencari kepiting di pantai

Atau pria-pria pencari ikan dan penangkap udang di laut

Berkumpul bunga dan berhimpun daun

Bagai buah-buah lebat di Maeoe atau di Soetimori

Bagai himpunan kerbau dan kawanan domba

Sehingga persatuannya tak goyang digoncang dan tak goyah digoyang

Karena mereka sehati bagaikan anak-anak seibu

Dan mereka sejiwa bagai anak-anak seayah

Sehingga terciptalah yang indah dan terwujud yang nyaman

Oleh karena itu, diberi sebutan dan diberi nama dan dikatakan atau di dibilang

Sotimori atau Telanai

Satido atau Saudo

Dan Balodo atau Oulilo 
Glossing dan Koding

Hida bei fan ma dato bei don ele (L 1.1)

Pada masih dahulu dan saat masih masa silam

'Di waktu yang lampau dan dimasa silam'

Bei ta lae Landu (L 1.2)

masih NEG sebut Landu

'Belum di sebut Landu'

Te ala loke lae Tanalai (L 1.3)

KONJ 3JM beri sebut Tanalai

'Tetapi mereka memberikan nama Tanalai'

Ma ala hule lae Mae Oe (L 1.4)

KONJ 3JM kasi sebut Mae Oe

'Dan dikasih nama oleh mereka Mae Oe'

Ma Setimori do Tenalai (L 1.5)

KONJ Setimori KONJ Tenalai

'Dan Setimori atau Tenalai'

Sotido do Saudo, ma Balodo do Oulilo (L 1.6)

Sotido KONJ Saudo, Konj BalodoKONJ Oulilo

'Sotido atau Saudo, dan Balodo atau Oulilo'

Ala aki dae do ala bala tola (L 2.1)

3JM nama beri KONJ 3JM sebut demikian

'Mereka memberi nama atau mereka menyebutnya demikian'

Ala loke do ala hule lae leo ndiana(L 2.2)

3JM loke KONJ 3JM hule kata seperti orang

'Mereka Loke dan mereka Hule seperti kata orang'

Hu hida bei fan na ma dati bei don lele na

PART pada masih lama dahulu KONJ pada masih lampau waktu lewat

‘Pada dahulu kala dan pada jaman Iampau' (L 2.3)

Touk ala mana-seko metik, ma mana-solo nikala (L 2.4)

Pria 3JM mengeruk pantai, KONJ mencari di tebinglaut

'Laki-laki pencari ikan di pantai dan pencari udang di tebing laut' 
do taek ala manandai tasila, ma manasolo poek ala KONJ Pria mereka memancing dilaut, KONJ menangkap udang 3JM 'Dan para lelaki memancing di laut, atau mereka menangkap udang' (L 2.5) Laka bua-bua buna, ma lake leme Maeoe diatas buahRED banyak, KONJ merangkul mengikat PRE Mae Oe 'Di atas pohon berbuah lebat, atau merangkul mengikat di Mae Oe' (L 3.1)

do Sotimoro ma selen te tini tihi (L 3.2)

KONJ Sotimoro KONJ tanam PART kebun tihi

'Dan Sotimoro menanam di kebun'

hu ala dalek esa leo inak esa bobongis(L 3.3)

hingga3JM rasa satu sepertibu satu kandungan

'Hingga mereka satu perasaan merasa seperti dari kandungan satu ibu'

ma ala teik esak leo touk easa lalaen de (L 3.4)

KONJ 3JM batin satu-KI seperti pria satu lalaen disana

lalek ala dadi

lalek 3JM menjadi

'dan mereka sejiwa, seperti dari satu ayah'

Ma ladak ala moli (L 3.5)

KONJ indah 3JM lihat

'Dan mereka terlihat indah'

Hu ndia de, ala aki dae do ala bala tola Hingga DEM disana, 3JM aki bumi KONJ 3JM timur muncul

'Bagai matahari terbit di ufuk timur'

Kerajaan Landu berdasarkan catatan sejarah tertulis sebagai salah satu kerajaan dari 19 kerajaan di Pulau Rote. Pulau Rote dikenal dengan sebutan "Lolo Neo Do Tenu Hatu" sebagai masyarakat dengan cara berbeda menyebutnya dengan sebutan "Nes Do Male" yang sama artinya dengan "Lino Do Nes" berarti pulau yang sunyi dan tanpa penghuni. Penamaan dan sebutan Rote diperkenalkan secara luas oleh pedagang- 
pedagang Portugis yang terkait erat dengan misionaris di Indonesia pada tahun 1512 1605.

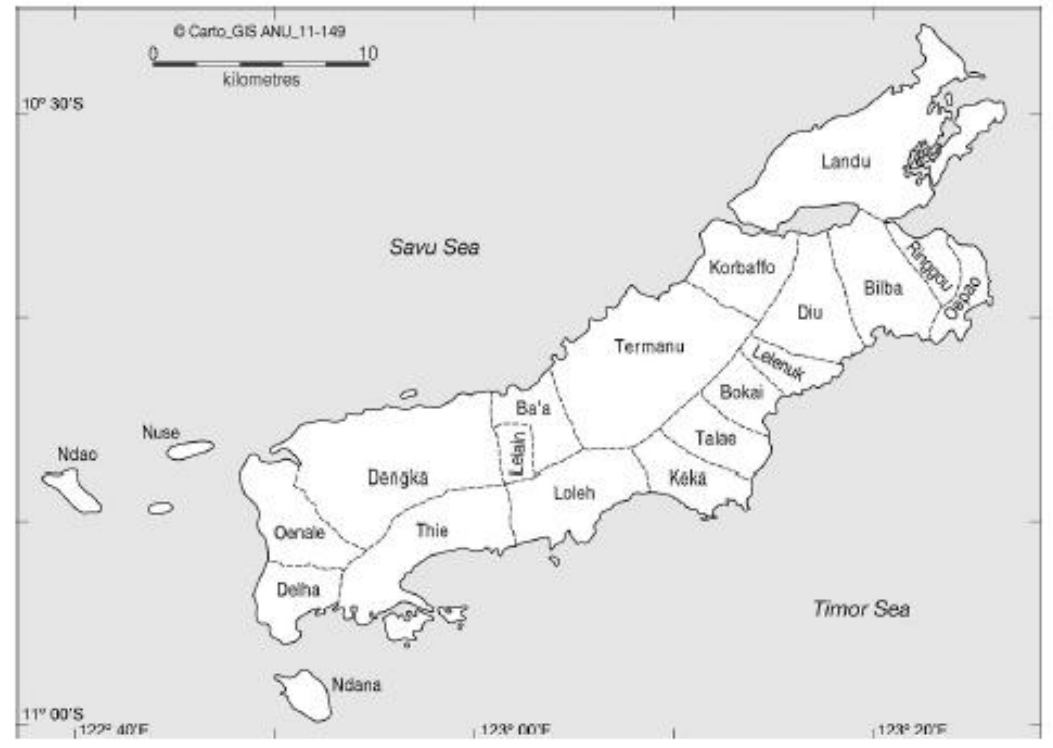

Gambar 1 Peta Kerajaan-Kerajaan di Rote

Berkaitan dengan catatan sejarah tersbeut, toleransi merupakan salah satu penciri globalisasin yang telah hadir pada abad ke-5. Toleransi berdasarkan konteks aslinya berkaitan dengan ketahanan dalam menghadapi penderitaan dan rasa sakit. Definisi ini kemudian berkembang menjadi kemampuan dalam bertahan atau menanggung suatu keadaan atau kondisi tertentu yang tidak sesuai dengan harapan. Pemaknaan ini berasal dari bahasa Perancis tolerance. Lebih lanjut, tepatnya pada 1765 toleransi bergeser menjadi sikap menerima terhadap berbagai perbedaan. Pemahaman toleransi berdasrkan Perez Zagorin, menjelaskan bahwa terminologi toleransi berkembang dalam displin ilmu sosial, budaya dan agama yang berarti sikap dan perbuatan yang melarang adanya diskriminasi terhadap kelompok-kelompok yang berbeda dalam batasan kemanusiaan. Deklarasi prinsip-prinsip toleransi oleh UNESCO menyatakan bahwa toleransi adalah rasa hormat, penerimaan, dan penghargaan atas keragaman budaya dunia yang kaya, berbagai bentuk ekspresi diri dan cara-cara menjadi manusia.Toleransi adalah kerukunan dalam perbedaan.

Sedangkan, konsep toleransi diterjemakan ke dalam konteks masyrakat Indonesia sebagai sikap saling menghormati dan menghargai antarkelompok atau antarindividu dalam masyarakat atau dalam lingkup lainnya. Sikap toleransi menghindarkan terjadinya diskriminasi, walaupun banyak terdapat kelompok atau golongan yang berbeda dalam suatu kelompok masyarakat.

Berdasarkan penelitian 20 toleransi didefinikan sebagai internalisasi nilai keberterimaan dan kesepahaman (acceptability and understanding). Selanjutnya, nilai-

${ }^{20}$ Marsi Bombongan Rantesalu and Iswanto Iswanto, “Toleransi Berdasarkan Cerita Rakyat Tallu To Sala' Dadi Di Toraja," BIA': Jurnal Teologi dan Pendidikan Kristen Kontekstual 1, no. 1 (2018): 13-25. 
nilai tersebut disejajarkan dengan kebersamaan (togetherness) dan saling melengkapi (complementary.. Berdasarkan nilai-nilai tersebut dikonsepkan definisi toleransi berdasarkan CRMT (Ceritra Rakyat Masyarakat Toraja) Tallu Tosalaqdadi adalah sikap menerima (acceptability) dan memahami (understanding) kekurangan dan perbedaan melalui kebersamaan (togetherness) dan saling melengkapi (complementary) untuk menghadapi tantangan (global) dan memperbaiki kekurangan diri sendiri.

Toleransi dalam CRMT Tallu Tosalaqdadi tidak semata dipandang sebagai sikap individu semata, tetapi sikap dalam sebuah tatanan sosial sebuah masyarakat. Definisi yang lebih konprehensif berkaitan dengan pandangan dunia (world view) dalam menghadapi konflik internal dan tantangan dari luar.

Berdasarkan paparan di atas nilai-nilai toleransi dalam CRMR (Ceritra Rakyat Masyarakat Rote) Landu dapat ditelisik berdasarkan data penelitiannya sebagai berikut. Matra I terdiri dari lima larik, yang memberikan informasi yang cukup tentang keinginan untuk hidup bersama dalam satu lingkup geografis. Seperti diungkapkan pada larik I dan seterusnya bahwa di daerah Landu terdapat nama-nama lain seperti Tanalai, Mae Oe, Setimori, Saudo, Balodo dan Oulilo. Bentuk penyepasangan diadik sebagaimana dijelaskan pada bagian struktur CRMR menjadi ciri khas yang menjelaskan bahasa ritual pada masyarakat Rote. Jika dihubungkan dengan penjelasan pada bagian pendahuluan yaitu pada ungkapan Tungga Manaparenda Dean 'keharmonisan dalam kehidupan' dapat tarik kesimpulan bahwa berdasarkan teks CRMR nilai toleransi yang mendasar yaitu keharmonisan.

Kajian ilmu sastra lisan menempatkan unsur makro seperti bunyi sebagai unsur yang penting dalam menganalisa sikap penuturnya. Iswanto (2018) menyatakan Pengkajian dengan pendekatan semiotik menyikapi bahwa setiap tuturan adalah "tanda" yang mengandung muatan makna. Kebermaknaan dapat terlihat dalam sistem penandaan pada tuturan tersebut. Simpulan yang tulisan seblumnya penanda-penanda keberlisanan sangat kompleks dan rumit dibedah, apalagi sikap penutur dan masyarakat partisipan yang masih memandang tuturan ritual memiliki kekuatan gaib, setiap hembusan nafas dalam tuturan mengandung sejuta makna kegaiban, sehingga kata-kata yang keluar dari mulut tidaklah sekadar kata-kata biasa. Tentu saja pembedahan tuturan akan mendekati sempurna jika peneliti mampu merasakan apa yang dirasakan, apa yang dipikirkan penutur bersama masyarakatnya. Jelaslah hal ini sangat sulit, untuk mencapai tujuan tersebut perlu kiranya peneliti menelusuri sistem penandaan yang digunakan dalam tuturan ritual tersebut.

Struktur CRMR yang tergambar pada matra I direkontruksi dari berbagai struktur penyepasangan diadik seperti hida//dato sebagai tanda waktu 'pada//saat'. Bentuk lingual diadik ini bergayut dengan bentuk lingual bei 'masih' sebagai bentuk lingual yang mempertegas pasangan diadik hida//dato sebagai tanda waktu 
'pada//saat'. Gayutan ini berkaitan secara sintagmatis dengan fan//ele yang diterjemahkan 'dahulu//silam'. Struktur matra ini menandakan asal-muasal wilayah Landu sebagai salah satu wilayah kerajaan kepulauan Rote.

Lebih lanjut, dijelaskan pada matra II dengan struktur penyepasangan seperti Setimori//Tenalai, Sotido//Saudo, Balodo//Oelilo termasuk di dalamnya Mae Oe dan Setimori. Penamaan daerah menjadi hal yang penting karena berkaitan dengan identitas masyarakat pada daerah tersebut. Jika dibuat interpretasi mendalam, maka dapat diajukan pertanyaan mengapa daerah Landu memiliki banyak nama, padahal luas pulau Landu tidaklah terlalu besar? Berdasarkan informasi yang diperoleh wilayah-wilayah tersebut dinamakan sesuai nama keluarga atau pemimpin kelompok yang berada di daerah tersebut.

Peta kognitif 1, memberikan gambaran alur pikir kompleks yang disebabkan struktur diadik pada matra I. Jika ditelusuri pada larik berikutnya, bentuk lingual ala 'mereka' juga menjelaskan keberadaan penghuni pulau Landu pada saat itu, yang terdiri dari beberapa kelompok. Bentuk lingual ama 'mereka' pada larik I terikat dengan verba diadik loke//hule 'beri//kasih' yang secara semantis terikat satu dengan yang lain. Verba diadik loke//hule 'beri//kasih' juga terikat dengan bentuk lingual lae 'sebut'. Struktur naratif yang lebih kompleks dapat terlihat bila matra I dijelaskan strukturnya oleh matra II, sebagaimana gambar di bawah ini.

Konsep tuturan ritual dipandang sebagai bahasa yang digunkan dalam ritus tertentu. Sedangkan ritual sendiri didefinisikan sebagai agama dalam tindakan. Lebih lanjut Dhavamony mengungkapkan bahwa ritus adalah tindakan simbolis sebagai gambaran pengalaman keagamaan dalam bentuk kultis. ${ }^{21}$

21 Dhavamony, Mariasusai, Fenomenologi Agama. Terjemahan Buku Phenomenology of Religion. (Yogyakarta: Kanisius, 1995). 


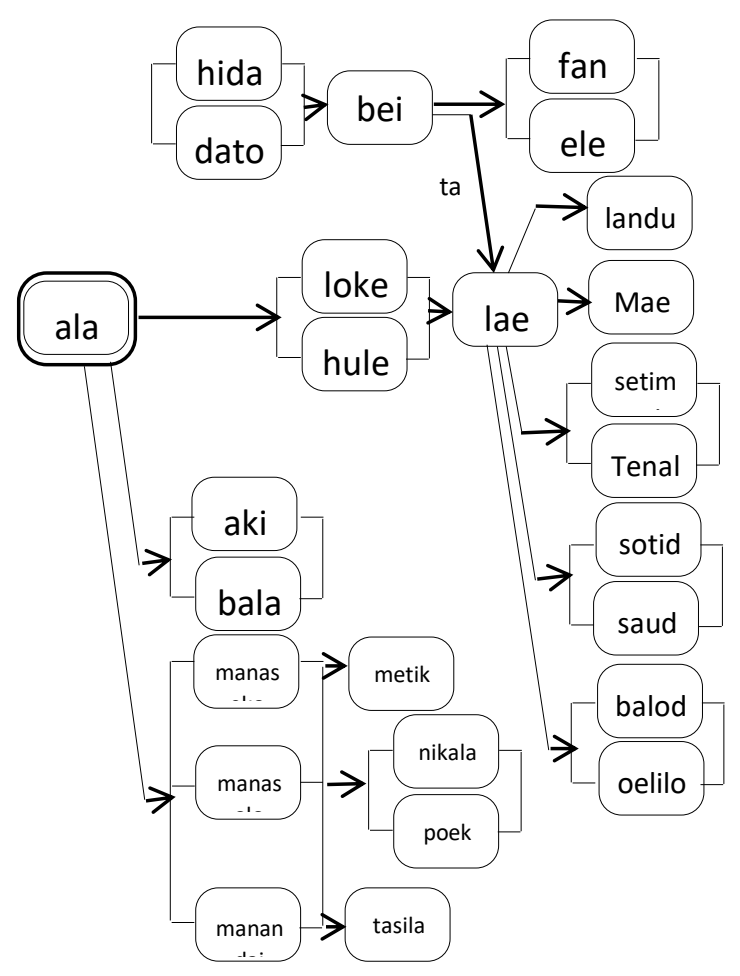

Peta Kognitif 1. Struktur Matra I. II

Peta kognitif 1, menunjukkan struktur penyepasangan diadik yang lebih kompleks. Bentuk penyepasangan yang ada seperti aki//bala 'nama//sebut', loke//hule, manaseko//manasolo 'mengeruk//mencari', manandai//manasolo 'memancing//menangkap'. Struktur narasi yang dibangun pada matra II memberikan sebuah informasi baru yang penting yaitu bagaimana keterkaitan identitas masyarakat Landu dengan kegiatan kehidupan keseharian yaitu pekerjaan di pantai dan mencari ikan di laut lepas. Struktur yang terbangun bukan langsung merujuk pada aktivitas lepas pantai, tetapi dimulai dari register pesisir yang ditandai dengan verba manaseko//manasolo 'mengeruk//mencari'. Kehidupan pesisir memegang peranan penting tidak hanya sebagai aktifitas dan atau mata pencaharian tetapi sebagai identitas kekerabatan. 


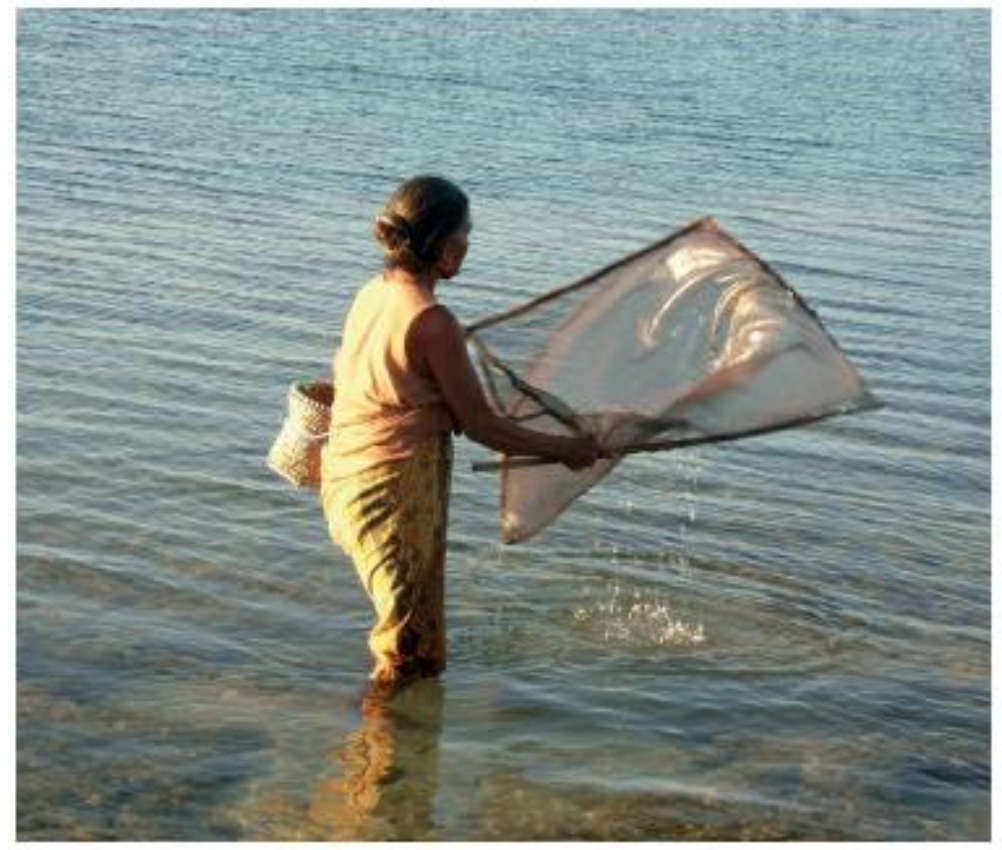

Gambar 2. Masyarakat Rote Mencari Ikan-ikan Kecil di Pesisir Pantai

Fox (1986: 106-108) menjelaskan mengenai sifat umum bahasa ritual, yaitu 1) bahasa ritual adalah suatu bentuk bahasa yang ditingkatkan dan dikembangkan dalam perangkat-perangkat diadnya yang tidak hanya berfungsi sebagai pengungkapan mentalitas semata. 2) Semua perangkat diad dalam bahasa ritual memiliki aturan dalam pengertian bahwa tiap perangkat merupakan suatu unit tradisional yang sudah tetap. 3) Bahasa ritual bersifat puitis dan metaforis, dalam batasa karaktek metafora yang dikendalikan oleh struktur diad. Ambiguitas dalam penggunaan unsur-unsur bahasa ritual sering lebih sedikit dibandingkan penggunaan unsur-unsur yang sama dalam bahasa sehari-hari. 4) Bahasa ritual menyajikan pemikiran pribumi yang tersusun rapih. 5) Perangkat-perangkat diad dalam bahasa ritual tidak hanya sekedar secara sistematis berasal dari unsur-unsur bahasa sehari-hari, tetapi juga secara sistematis berkaitan satu sama lain dalam lingkungannya.

Analisis sosial yang lebih luas dapat dikaitkan dengan beberapa fakta sejarah yang dapat dikaitkan dengan CRMR Landu yaitu: 1) struktur masyarakat yang terdiri dari beberapa kelompok (Heterogeneous society), keadaan geografis yang dapat mendukung kehidupan seperti tersedianya air tawar, hewan, tanaman umur pendek yang melimpah dan potensi lautan menjadi alasan kelompok-kelompok tersebut mendiami pulau Rote. 2) Keinginan untuk membagi daerah tempat kecil tetapi tetap dalam satu ideologi. Karakteristik suku-suku di Indonesia ialah satu kelompok suku 
yang terdiri dari beragam identitas yang khas dan berkelompok dalam daerah yang lebih kecil. Interaksi sosial akan menyebabkan munculnya kesepahaman yang tertuang dalam hukum adat. Lebih lanjut akan dipaparkan peta kognitif penjelas relasi leksikon matra I dan II. Dalam peta kognitif ini dapat terbaca alur teks dan interpretasi sosial yang mendalam berndasarkan teks tersebut. Atribut-atribut toleransi dalam masyarakat haruslah dijelaskan dengan kekhasan simbol atau leksikon yang dimiliki oleh masyarakat tersebut. ${ }^{22}$

Pemaparan yang lebih luas akan menjelasakan hubungan asosiatif antara satu leksikon dengan leksikon lainnya. Konteks yang dikontruksikan menandakan pemahaman masyarakat Landu tentang toleransi itu sendiri. Hal ini akan berkaitan satu dengan yang lainnya termasuk sistem kognisi tentang ekologi, budaya dan kosmologi. Memang tidak mudah untuk mengkonsepkan secara utuh suatu makna berdasarkan teks ritual. Asumsi yang dibangun harus berdasarkan teks ritual tersebut bukan preasumsi yang meluas. Berdasarkan data CRMR Landu berikut ini tergambar alur pikir teks tersebut.

\footnotetext{
${ }^{22}$ Yance Z Rumahuru, “Ritual Sebagai Media Konstruksi Identitas:” (n.d.): 9.
} 


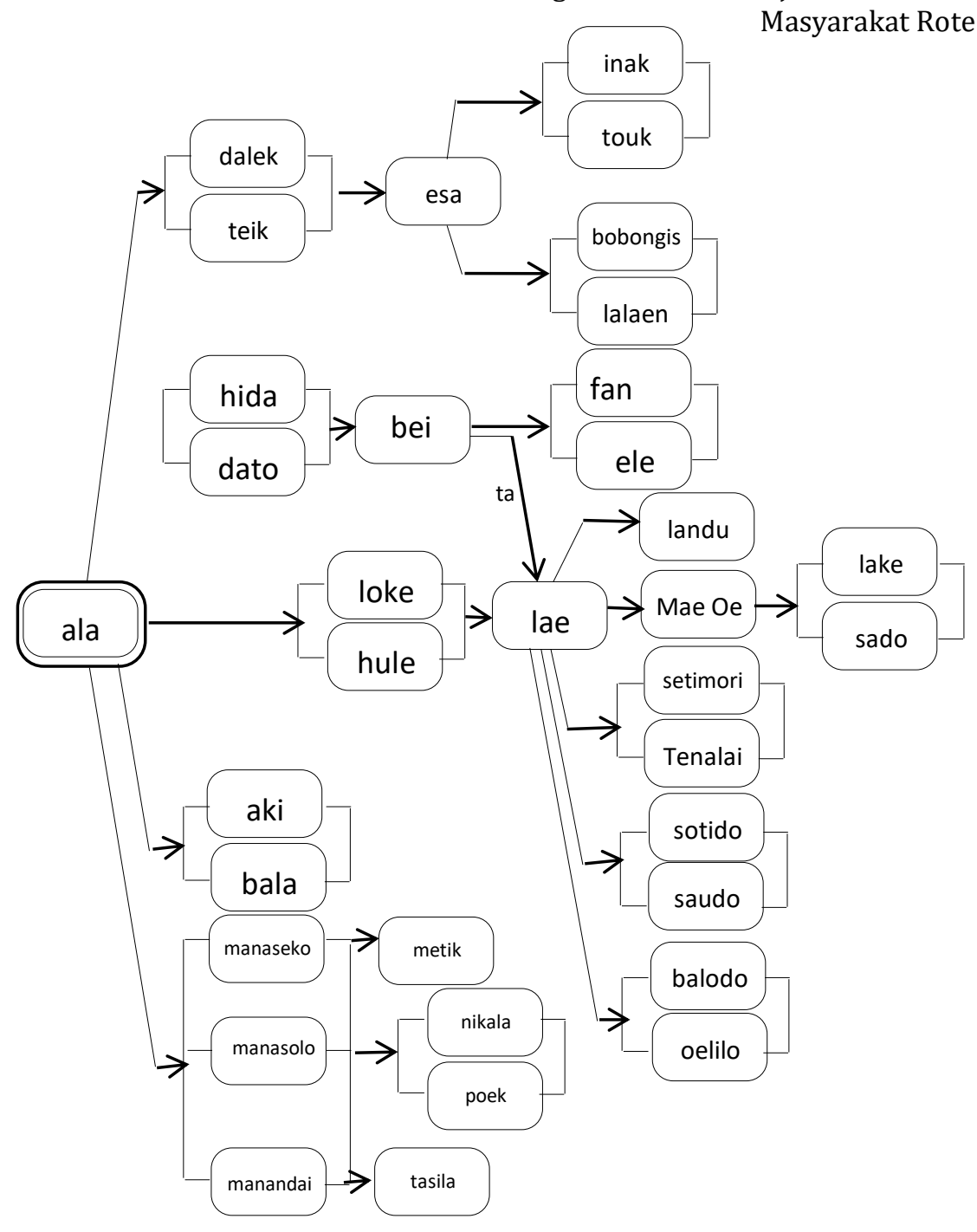

Peta Kognitif 2. Struktur Matra I, II Lundu

Peta kognitif 2, menjelaskan struktur penyepasangan diadik yang unik yaitu bentuk lingual dalek//teik 'rasa//batin'. Penggunaan kedua bentuk lingual ini diikuti dengan bentuk lingual esa( $k$ ) 'satu' yang berasosiatif dengan penyepasangan inak//touk 'ayah//ibu'.

Istilah pararelisme muncul pertama kali pada abad ke-18 dan berasal dari penelitian Robert Lowth dengan objek penelitian puisi-puisi Ibrani. Dalam hal ini, pararelisme diartikan sebagai kesesuaian atau kecocokan suatu bait atau baris dengan bait atau baris lainnya. Selanjutnya, Roman Jacobson dalam Fox ${ }^{23}$ berpendapat bahwa pararelisme adalah aspek yang selalu hadir dalam bahasa puitik. Sehingga pararelisme mencerminkan perluasan dari prinsip biner oposisi terhadap tataran-tataran ekspresi fonemis, sintaktis dan semantis.

${ }^{23}$ James J. Fox, ed., To Speak in Pairs: Essays on the Ritual Languages of Eastern Indonesia, Cambridge studies in oral and literate culture 15 (Cambridge ; New York: Cambridge University Press, 1988). 
Dalam tradisi keberlisanan jelaslah bahwa bunyi adalah tanda yang terindrai menjadi ciri karakteristik tuturan, apalagi tuturan ritual. Verba diadik loke//hule 'beri//kasih' dalam benak masyarakat pemilik budaya tidak hanya bermakna harafiah tetapi di dalamnya terdapat unsur keberterimaan dan kesepahaman yang menjadi salah satu nilai toleransi. Toleransi sebagai bagian dari dialektika globalisasi ditimbulkan dari sikap saling menerima perbedaan (accepting defferance). Hal ini tidak semata-mata didorong oleh persepsi globalisasi tetapi sikap yang telah ada pada masyarakatmasyarakat di seluruh dunia. ${ }^{24}$ Berdasarkan hasil wawancara ${ }^{25}$ cerita rakyat Landu tidak hanya mengkisahkan tentang asal-usul daerah ini. Cerita ini lebih tepatnya merupakan bagian dari cerita-cerita asal-usul masyarakat Rote. Bagian-bagian cerita mengungkapkan bahwa sebenarnya masyarakat Rote terdiri dari berbagai kerajaankerajaan yang tersebar di pulau Rote. Para raja menyatukan kerajaan ini dengan ideologi 'sasangko' yang menggambarkan tubuh manusia dan berbagai unsur marga atau klan. Jika digambarkan dalam diagram akan membentuk alur narasi sebagaimana dipaparkan berikut ini

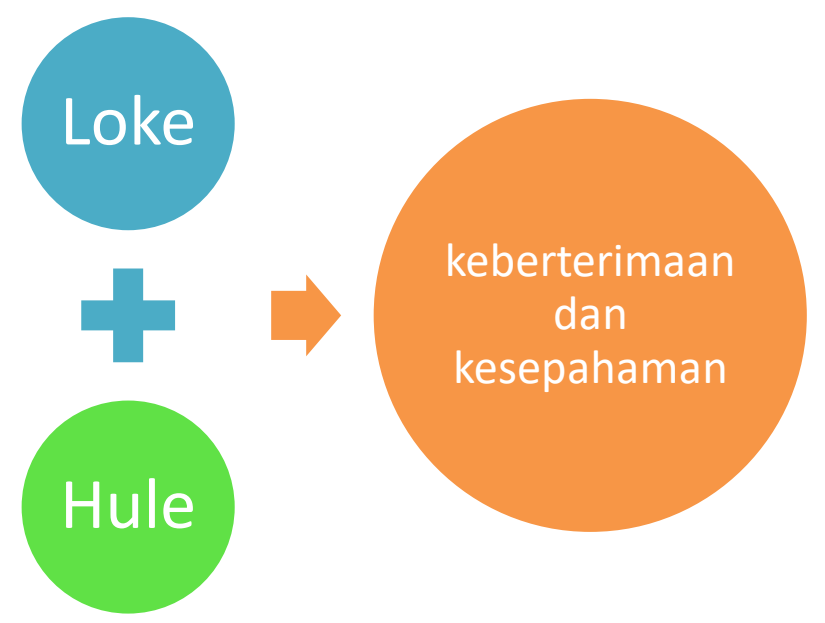

Gambar 3, Nilai Toleransi CRMR Matra I

Nilai keberterimaan dan kesepahaman (acceptability and understanding) ini sebagai alas dasar toleransi dijelaskan berdasarkan verba diadik loke//hule 'beri//kasih'. Lebih lanjut, sebagaimana dalam matra II dijelaskan sebagaimana data di bawah ini.

Ala aki dae do ala bala tola (L 2.1)

3JM nama beri KONJ 3JM sebut demikian

'Mereka memberi nama atau mereka menyebutnya demikian'

${ }^{24}$ Barry K. Gills, "Accepting Difference, Finding Tolerance, Practising Dialogue," Globalizations 3, no. 4 (December 2006): 423-426.

25 Wawancara: Meldi Monash, Lobalain-Rote Ndao, 15-16 Juli 2019, Pkl. 10.00 WITA 
Ala loke do ala hule lae leo ndiana (L 2.2)

3JM loke KONJ 3JM hule kata seperti orang

'Mereka Loke dan mereka Hule seperti kata orang'

$\mathrm{Hu}$ hida bei fan na ma dati bei don lele na

PART pada masih lama dahulu KONJ pada masih lampau waktu lewat

'Pada dahulu kala dan pada jaman lampau' (L 2.3)

Touk ala mana-seko metik, ma mana-solo nikala (L 2.4)

Pria 3JM mengeruk pantai, KONJ mencari di tebinglaut

'Laki-laki pencari ikan di pantai dan pencari udang di tebing laut'

do taek ala manandai tasila, ma manasolo poek ala KONJ Pria mereka memancing dilaut, KONJ menangkap udang 3JM

'Dan para lelaki memancing di laut, atau mereka menangkap udang' (L 2.5)

Sikap dan perilaku hidup keberterimaan dan kesepahaman (acceptability and understanding) menjadi dasar untuk saling membantu dan saling mengerti dalam kehidupan. Konsep kehidupan pada matra II CRMR Landu berkaitan erat dengan mata pencaharian sebagai pencari ikan dan udang, baik di pesisir, di tebing, dan di laut. Verba diadik yang menjelaskan hal tersebut ialah loke//hule, manaseko//manasolo 'mengeruk//mencari', manandai//manasolo 'memancing//menangkap'. Jika alur narasi disejajarkan dengan alur nilai dapat digambarkan sebagaimana di bawah ini.

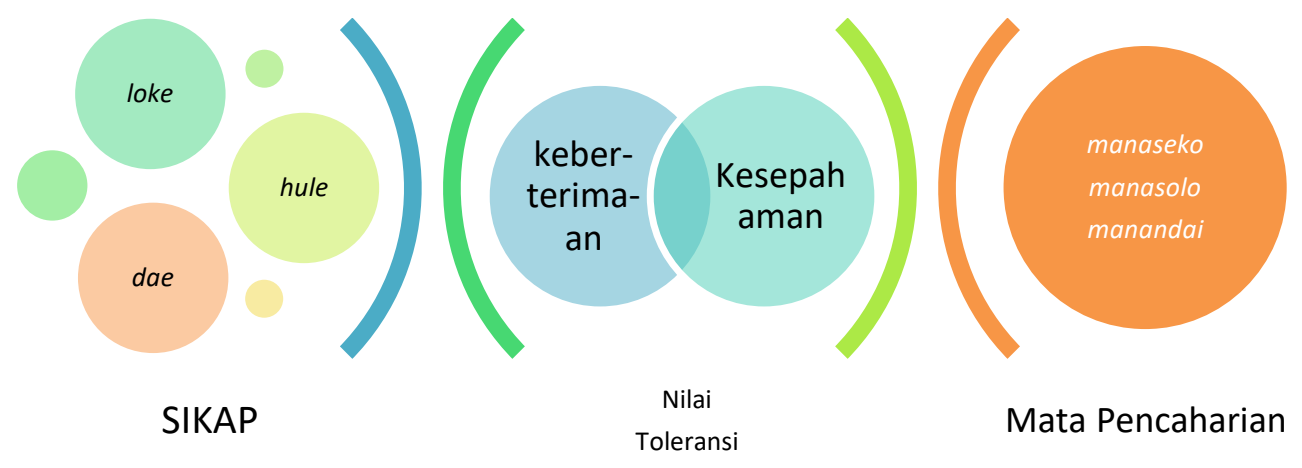

Gambar 4, Nilai toleransi dalam Narasi Sikap dan Mata Pencaharian 
Berdasarkan gambar 4, dapat dijelaskan bahwa toleransi terbentuk dari sikap keberterimaan dan kesepahaman (acceptability and understanding) yang dalam CRMR Landu sepadan dengan bentuk lingual loke//hule 'beri//kasih' dan dae 'beri'. Keterkaitan ini disampaikan lewat melalui bentuk penyepasangan verba yang menjadi ciri pararelisme. Lebih lanjut, hubungan yang signifikan juga tergambar dalam keseharian yaitu bagaimana masyarakat Landu bekerja manaseko//manasolo 'mengeruk//mencari', manandai//manasolo 'memancing//menangkap'. Dengan demikian, dapat dijelaskan nilai toleransi dilaksanakan pada tataran keseharian.

Penelusuran narasi yang lebih mendalam dapat dilakukan melalui informasi pada matra III, sebagaimana data di bawah ini.

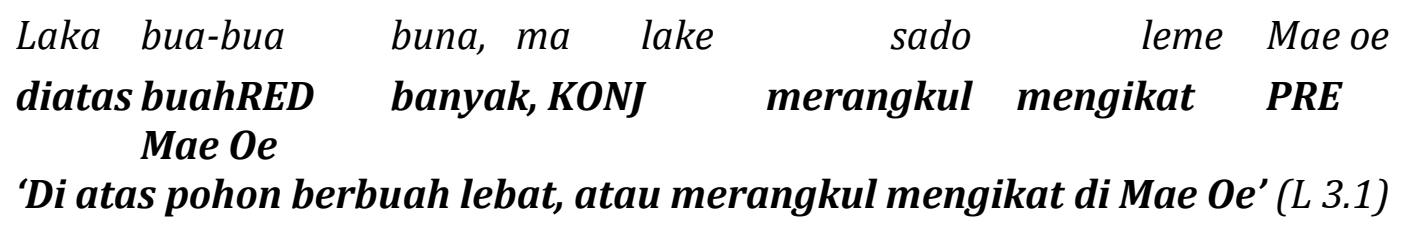

do Sotimoro ma selen te tini tihi (L 3.2)

KONJ Sotimoro KONJ tanam PART kebun tihi

'Dan Sotimoro menanam di kebun'

hu ala dalek esa leo inak esa bobongis (L 3.3)

hingga3JM rasa satu sepertibu satu kandungan

'Hingga mereka satu perasaan merasa seperti dari kandungan satu ibu'

ma ala teik esak leo touk easa lalaen de (L 3.4)

KONJ 3JM batin satu-KI sepertipria satu lalaen disana

lalek ala dadi

lalek 3JM menjadi

'dan mereka sejiwa, seperti dari satu ayah'

Ma ladak ala moli (L 3.5)

KONJ indah 3JM lihat

'Dan mereka terlihat indah' 
Berdasarkan data di atas, dapat dijelaskan keselarasan makna dari struktur penyepasangan diadik yang unik yaitu bentuk lingual dalek//teik 'rasa//batin'. Penggunaan kedua bentuk lingual ini diikuti dengan bentuk lingual esa(k) 'satu' yang berasosiatif dengan penyepasangan inak//touk 'ayah//ibu'. Jika dilihat dari maknanya maka data L3.3 berbunyi

hu ala dalek esa leo inak esa bobongis(L 3.3)

hingga3JM rasa satu sepertiibu satu kandungan

'Hingga mereka satu perasaan merasa seperti dari kandungan satu ibu'

Kata seperti dari satu kandungan mengandung arti bahwa orang-orang yang berinteraksi di daerah tersebut dan dalam konteks itu bukanlah sudara kandung tetapi dipersatukan dalam satu perasaan yang sama seperti dari satu kandungan. Prinsip dasar toleransi keterbukaan dan universalisme. Sastra lisan nusantara menunjukkan alur nilai keterbukaan dan setiap plot yang disajikan. Hal ini juga terdapat pada teks landu pada masyarakat Rote. Struktur sosial yang baku, dapat terlihat dari marga atau klan. Struktur sosial akan membangun nilai kerbesamaa, nilai kerja, nilai sosial, dan nilai inklusifitas. Dari interpretasi ini, dapat ditarik alur makna nilai persaudaraan (brotherhood) sebagai nilai toleransi tertinggi dalam CRMR Landu. Keseluruan pemaparan di atas, jika digambarkan akan terlihat sebagai berikut.

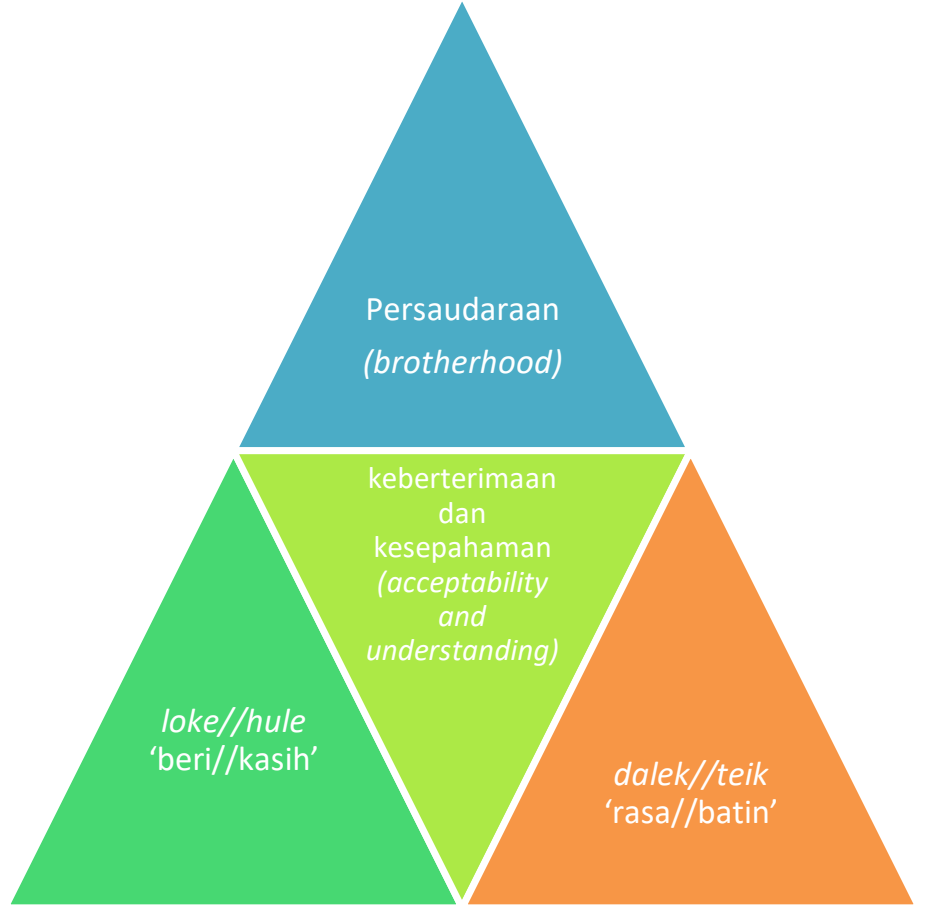

Gambar 5, Nilai Toleransi Berdasarkan CRMR Lundu 


\section{Kesimpulan}

Struktur CRMR Landu terstruktur atas verba diadik yaitu hida//dato 'pada//saat', fan//ele 'dahulu//silam', Setimori//Tenalai, Sotido//Saudo, Balodo//Oelilo, loke//hule 'beri//kasih', aki//bala 'nama//sebut', loke//hule, manaseko//manasolo 'mengeruk//mencari', manandai//manasolo 'memancing//menangkap', manaseko//manasolo 'mengeruk//mencari', dalek//teik 'rasa//batin', inak//touk 'ayah//ibu'. Struktur ini terkait satu dengan yang lainnya dan berpusat pada bentuk lingual ala 'mereka'.

Nilai toleransi yang terdapat dalam CRMR Landu adalah (1) Nilai keberterimaan dan kesepahaman (acceptability and understanding) ini sebagai alas dasar toleransi dijelaskan berdasarkan verba diadik loke//hule 'beri//kasih' dan (2) nilai persaudaraan (brotherhood) yang berdasarkan pada bentuk diadik dalek//teik 'rasa//batin', inak//touk 'ayah//ibu'.

Kajian teks menjadi salah satu model penelitian yang mampu mengungkapkan makna budaya toleransi. Kekayaan atribut yang ada tertuang dalam leksikon bahasa daerah yang khas sebagai penggambaran dunia (word view) masyarakat Rote. Diskusi lebih lanjut akan mengarah pada penelitian dengan korpus data yang lebih besar untuk mencari atribut budaya pemaknaan toleransi. Dengan semakin beragamnya atribut budaya tersebut akan diketahui sistem kognisi sosial toleransi yang ada pada suku-suku di Indonesia.

Saran dalam penelitian ini ialah (1) upaya revitalisasi sastra dan budaya masyarakat Rote menjadi hal penting yang harus dilakukan oleh seluruh jajaran dan instansi terkait; (2) berbagai nilai-nilai toleransi dalam CRMR adalah sebuah interpretasi berdasarkan teks budaya sehingga di dalamnya perlu usaha untuk tetap menjaga nilai-nilai tersebut berdasarkan pranata budaya yang ada; (3) pemerintah, khususnya kabupaten Rote Ndao harus berupaya secara terus-menerus menyiapkan program pembangunan berbasis budaya Rote khususnya yang bersumber pada teks budaya setempat; (4) para praktisi toleransi dan akademisi hendaknya senantiasa mengembangkan konsep toleransi yang tidak hanya berdasarkan fenomena masa kini, tetapi kearifan tataran sikap dan perilaku dalam budaya-budaya asli masyarakat Indonesia.

\section{Referensi}

Akhiyat, Akhiyat. "Debates on Religious Studies In the Phenomenology Perspective and Its Contribution to Interfaith Tolerance." Ulumuna 23, no. 1 (June 28, 2019): 163-192.

Andurand, Anthony, and Corinne Bonnet. "The Divine Plato among Greeks and Romans: Banquet Literature and the Making of Cultural Memory in the Graeco-Roman Empire" (2018): 13. 
Barthes, Roland. Mitologi. (Terj. Nurhadi \& Sihabul Millah). Yogyakarta: Kreasi, n.d.

van Bowen, Theodora. “Religious Education For Tolerance.” Utrecht (2016): 59.

Corneo, Giacomo dan Olivier Jeanne. A Theory of Tolerance. London: Johns Hopkins University, 2009.

Danesi, Marcel. A Basic Course in Anthropological Linguistic. Toronto: Canadian Scholar's Press inc, 2004.

Dhavamony, Mariasusai. Fenomenologi Agama. Terjemahan Buku Phenomenology of Religion. Yogyakarta: Kanisius, 1995.

Fox, James J. "The Poetic Power of Place: Comparative Perspectives on Austronesian Ideas of Locality" (n.d.): 89-93.

Fox, James J., ed. To Speak in Pairs: Essays on the Ritual Languages of Eastern Indonesia. Cambridge studies in oral and literate culture 15. Cambridge; New York: Cambridge University Press, 1988.

Gallagher, Shaun, and Dan Zahavi. The Phenomenological Mind: An Introduction to Philosophy of Mind and Cognitive Science. Repr. London: Routledge, 2010.

Gills, Barry K. "Accepting Difference, Finding Tolerance, Practising Dialogue." Globalizations 3, no. 4 (December 2006): 423-426.

Hefner, Robert W., and Barbara Watson Andaya, eds. Routledge Handbook of Contemporary Indonesia. Routledge handbooks. Abingdon, Oxon ; New York, NY: Routledge, 2018.

Iswanto, et al. "Supernatural Signification System Amuf on Death Ritual Speech Nen Fen Nahat in Boty Society." International Journal of Linguistics, Literature and Culture, 4(2), March 2018, 46-57 Vol 4 No 2 (2018). Retrieved from https://sloap.org/journals/index.php/ijllc/article/view/87.

Rantesalu, Marsi Bombongan, and Iswanto Iswanto. "Toleransi Berdasarkan Cerita Rakyat Tallu To Sala' Dadi Di Toraja." BIA': Jurnal Teologi dan Pendidikan Kristen Kontekstual 1, no. 1 (2018): 13-25.

_- - “Toleransi Berdasarkan Cerita Rakyat Tallu To Sala' Dadi di Toraja." BIA': Jurnal Teologi dan Pendidikan Kristen Kontekstual 1, no. 1 (December 30, 2018): 13-25.

Ricœur, Paul, and John B. Thompson. Hermeneutics and the Human Sciences: Essays on Language, Action, and Interpretation. New York: Cambridge University Press, 2016.

Rumahuru, Yance Z. “Ritual Sebagai Media Konstruksi Identitas:” (n.d.): 9. 
de Saussure, Ferdinant. Pengantar Linguistik Umum. Yogyakarta: Gajah Mada University Press, 1993.

Thibault, Paul J. Re-Reading Saussure: The Dynamics of Signs in Social Life. London ; New York: Routledge, 1997.

Zaluchu, Sonny, and Fransiskus Widjaja. "A Phenomenology Approach: Religious Significance of Mandala in Ancient Nias Culture." In Proceedings of the Proceedings of the 1st Seminar and Workshop on Research Design, for Education, Social Science, Arts, and Humanities, SEWORD FRESSH 2019, April 27 2019, Surakarta, Central Java, Indonesia. Surakarta, Indonesia: EAI, 2019. Accessed September 17, 2020. http://eudl.eu/doi/10.4108/eai.27-4-2019.2286915.

Zlatev, Jordan. "Cognitive Semiotics: An Emerging Field for the Transdisciplinary Study of Meaning." Public Journal of Semiotics 4, no. 1 (October 1, 2012): 2-24. 